\title{
Study on the Image Variation of Nezha in the Movie Nezha*
}

\author{
Wenhui Chen \\ School of Foreign Languages \\ Kunming University \\ Kunming, China 650214
}

\begin{abstract}
As one of the representatives of Chinese traditional culture, Nezha is very familiar to Chinese people of many generations. Nezha's image is varied during this process of cultural transportation or heritage, and his image variation reflects the contemporary social and cultural modes. This image in the movie Nezha in 2019 is reconstructed as a child who bears heavy social prejudice due to his birth and longs for social identification to be a real hero. The image variation of this Nezha is the reflection of the present social context and this is also the value to research the image variation of Nezha in this movie.
\end{abstract}

Keywords-Nezha; image variation; reconstruction; cultural heritage

\section{INTRODUCTION}

As far as the influence of the images in the Chinese novels of God-evil novels, Nezha is unavoidably mentioned besides Sun Wukong and Zhu Bajie. In 2019, the story of Nezha is adapted once more into movie with great achievements and welcomed warmly in China. In this summer, this movie Nezha is the annual box-office champion and is also the first time for the homemade cartoon movie to gain this annual honor. The success of the movie attracts the academic research for it, and almost half of hundred research papers and news can be found in various journals and newspapers. These researches generally contain four perspectives such as the adaptation of the plot, the images of Nezha, the ethic family education and marketing strategies. In this paper, the image of Nezha, reconstructed in the movie of Nezha in 2019, is mainly analyzed.

\section{THE IMAGE OF NEZHA IN THE MOVIE NEZHA}

The great achievements of the movie even push it to compete for the Academic Awards on behalf of the China mainland.

In the movie, Nezha is born as a demon pill with an accidently mistake from a bead with huge power which is born from the universe spirit. The bead is divided into two - the holy pearl and the demon pill — by the God of the Original beginning. The former reincarnates into a hero who

*Fund: The Project is supported by Social \& Humanities Science Research Affairs Office of Yunnan Province in 2019; "Research on the Contextuality and Image Variation of the English Translation for Chinese Ancient Poems" (YB2019056) can help the king to fight against the enemies and the latter becomes into demon and brings disasters to the world. Then, the thunders appear three years later from the God's incantation to destroy the demon pill and save the world. However, the holy pearl is exchanged with the demon pill occasionally, and thus Nezha who should have be a hero become a demon but still has the dream of hero in his heart. As a child, Nezha is hated by the people outside the world due to his naughty but is loved by his parents. Facing popular misunderstanding or prejudice, the imminent devastating thunder, and longing for the recognition from everybody, Nezha struggles against the worldly prejudice and the demonic enemies. He saves the world and becomes the real hero.

Although the present image of Nezha is the evolutional result from the interchange and fusion of various Chinese religious culture, the image is comparatively fixed as a child hero who is the son of a god with a tower in his left hand and a general who is skillful in battle. With the appearance of a seven-year old child, Nezha has several magic weapons with great power for each one, and he even beat the son of the Dragon King to death. His image contains complication of goodness and naughty.

\section{ThE IMAGE VARIATION OF NEZHA IN THE MOVIE NEZHA}

With the Chinese national policy of cultural transportation, Chinese traditional culture is transported to the western countries with various forms, including the adaptation of the god-evil novels into the movies, and the story of Nezha is a good representation for Chinese culture to "go abroad".

\section{A. The Theory of Image Variation}

In the homemade cartoon movie Nezha, the image of Nezha is varied, compared with those in the famous classic novels such as Investiture of the Gods and A Journey to the West. The variation of images can be found anytime and anywhere in the process of cultural transportation. In the literary field, image is important and so is the image research. The theory of image originates from the French word "imagologie", the initiative scholar of this theory, JeanMarie Carre, defines it as the inter-interpretation between different ethic groups, travelogues and imagination [1]. The other representative of this theory, Daniel-Henri Pageaux, 
thinks that the image is the totality of the knowledge for the foreign countries in the process of socialization, and more explicitly, it is the special manifestation, i.e. the description to "the other". Then, Pageaux gives out the connotation of the theory that all the images originates the selfconsciousness although they are not so easy to be found, and they are the selves which are compared with "the others", or the right-here consciousness which is compared with the right-there consciousness. And so an image is the literary or non-literary expression, which means the gap between the two cultures and relationships of the signified and the signifier. [2] The scholar, Jean-Marc Moura, believes that the foreign images are from the foreign ethnic societies and cultures and are created according to the special feelings from the authors.[3] Chinese famous comparative scholar, Cao Shunqing, summarizes the theory from four perspectives. Firstly, an image is the description to a certain foreign historical and cultural reality from the perspective of the content; secondly, an image is the mixture with the strong subjectivity from the observer or the imaginer according to the generative mechanism; thirdly, from the form of expression, all the images are made or described by the means of peaking or writing, etc.; then, the foreign images do not always match the realities, and the image research value is the cultural modes of the creators reflected from the images, instead of the degrees of the matching between the prototypes and the images.[4] In the movie Nezha, the image of Nezha shows not only the Chinese traditional culture but also the image variation of the hero in the cultural heritage and transportation.

\section{B. The Image Variation of Nezha's Appearance}

As an image welcomed by Chinese people, Nezha evolves a long period of time from the Tang Dynasty to nowadays. Since the novel Investiture of the Gods is accepted popularly in China, the image of Nezha is fixed relatively. He is born as a white, fat and lovely child with clear-cut voice after his mother's three-year pregnancy. Despite being a kid, he has incredibly magnificent power with his magic weapons such as Qiankun Hoop on his neck, flaming spear in one of his hands, hot wheels under his feet, and some other magic weapons. He is the son of General $\mathrm{Li}$ Jing, but makes many troubles for his parents, which also leads to the bad relationships between the father and the son. He kills the son of the old dragon king, and hurts the old dragon king and some other innocent people. Under the unbearable pression, his father wants to kill his son to compensate the dragon family. With the burst out of the contradictions, Nezha commits suicide and then is resuscitated by his master, a Taoism immortal, with lotus roots and leaves. After his resuscitation which is also the change of his fate, Nezha has good relationship with his father and becomes a real Taoism immortal.

However, in the movie, the image of Nezha is varied with different birth, appearance, oral language, relationship with his father and the changes of his fate. According to the plot of the movie, the generally visually color for Nezha is somewhat dull black, due to the incarnation of the demon pill. As a child, Nezha is a little thin and ugly with two big black eyes and irregular teeth, and his voice is a bit hoarse. His hands are always in the trousers pockets when he walks, and fashionable words can be heard from his mouth. The incarnation of the demon pill gives him furious and mischievous temper. His ugly appearance and furious temper reflects his inner world on the contrast. He longs for the caring, love and approval from the local people though he is always given the prejudice, hostility, ridicule and reject. Nezha has very good relationship with his father in the movie, and his father gives him much love and protection because of the incarnation from the heaven to the demon pill which appears when Nezha is three-year old. Though he is naughty and regarded as the demon pill, Nezha's dream to being a hero is realized after he fights against the dragon family and saves all of the people and the world. His fate is changed and he is accepted as a hero by the world.

With some variation of the birth, appearance, characters, behavior, the changes of the fate and even the relationship with his father, the core of the Chinese traditional culture from Nezha's story is still kept in the movie.

\section{The Reasons for the Image Variation of Nezha}

The movie Nezha successfully inherits and passes down the Chinese traditional culture to the present new generation and tries to transport abroad the Chinese traditional culture; it is possible and unavoidable of the image variation during the process of the cultural heritage or transportation.

Professor Cao's theory of image variation pays more attention to the horizontally cultural transportation between the two heterogenous languages, but the image variation takes place not only between the heterogenous languages or cultures, but also within the same language or culture vertically with the evolution of the time and societies, such as the variation of Nezha's image from the novel Investiture of the Gods to the movie Nezha in 2019.

However, it should be remembered that an image is the mixture with the strong subjectivity from the observer or the imaginer according to the generative mechanism and the value for the image research is the cultural modes of the creators reflected from the images. Then, Nezha's image variation in the movie not only shows the present social realities but also pushes the acceptance of the heritage and the transportation of the Chinese culture home and abroad.

Whether cultural transportation or heritage, combined with the humanistic and geographical context, culture is given new connotation to fit for the ideology in the different eras, expressing ideas, feelings and expectations, and this is the dynamic cultural heritage or transportation. [5] In the movie, Nezha gains the new image of the new era, and he maybe is the representative of people who are always struggling for their dreams. With heavy social pressure, hard work is necessary for many people to change their fates, even they are given some prejudice. This is the contemporary social reality and is also the research value for Nezha in the new era, i.e. the individual growth, the realization of individual values and fighting against prejudice. 


\section{CONCLUSION}

The image of Nezha is reconstructed and varied in the movie Nezha in 2019. This is the value of the Nezha's image variation in this warmly-welcomed movie, and is also the value for the cultural heritage and transportation from the image of Nezha representing the core of the Chinese traditional culture. It can be predicated that more image variation for Nezha can be found by various means of heritage and transportation in the future and image variation is the necessity for the acceptance of Chinese traditional cultural heritage and transportation home and abroad.

\section{REFERENCES}

[1] D. H. Pageaux. "From the Cultrural Image to the Collective Imagination". The Imagology of Comparative Literature, Meng, H., Eds. Beijing: Beijing University Press, 2001, pp.2.

[2] D. H. Pageaux, "From the Cultrural Image to the Collective Imagination". The Imagology of Comparative Literature, Meng, H., Eds. Beijing: Beijing University Press, 2001, pp.120-125.

[3] D. H. Pageaux, "From the Cultrural Image to the Collective Imagination". The Imagology of Comparative Literature, Meng, H., Eds. Beijing: Beijing University Press, 2001, pp.25.

[4] Cao, S. Q., Comparative Literature. Chengdu: Sichuan University Press, 2005, pp. 207.

[5] Wu J, "On the Interpretation of the Cultural Semeotics for Nezha", Journal of Literature and History, 2013, vol. 1, pp. 26-29. 